\title{
Desalination using algae ponds under nature Egyptian conditions
}

\author{
El Nadi M. H. A. ${ }^{1}$, El Sergany F. A. G. H. ${ }^{2}$, El Hosseiny O. M. ${ }^{3}$ \\ ${ }^{1}$ Public Works Dept., Faculty of Eng., ASU, Cairo, Egypt \\ ${ }^{2}$ Civil Eng. Dept., HIT, $10^{\text {th }}$ of Ramadan City, Egypt \\ ${ }^{3}$ Civil Eng. Dept., Future Univ., Cairo, Egypt
}

\section{Email address:}

mhnweg@yahoo.com (E. Nadi M. H. A.), fatenelsergany@gmail.com (E. Sergany F. A. G. H.), Cloudvii@gmail.com (E. Hosseiny O. M.)

\section{To cite this article:}

El Nadi M. H. A., El Sergany F. A. G. H., El Hosseiny O. M.. Desalination Using Algae Ponds under Nature Egyptian Conditions. Journal of Water Resources and Ocean Science. Vol. 3, No. 6, 2014, pp. 69-73. doi: 10.11648/j.wros.20140306.11

\begin{abstract}
This study aims to study the suitability of using algae for water desalination as a new conceptual technique using algae ponds under the nature circumstances. A pilot unit consisted of three serial basins each divided to three parallel basins was erected outdoor in open area to be under natural climatic conditions. The algae were prepared in the lab using BG11 media to encourage its growth under saline water then put in the basins with $0.4 \mathrm{lit} / \mathrm{path} / \mathrm{run}$ for algae rate and 0.1 lit/path/run for BG11 rate. The basins fed by several concentrations from saline water from $2000 \mathrm{ppm}$ till 40000 ppm with several runs to get the TDS removal efficiency. The experimental work shows that the removal efficiency for TDS in the first basin varied between $61 \& 80.5 \%$ and became after second basin between $71 \& 93 \%$ which increased by third basin to 83 to $97.7 \%$. These variations were due to inlet TDS concentration and the climatic conditions (Temperature \& sunlight period). The results achieved high removal efficiency for TDS and the results in the highest inlet concentration were inside the permissible limits for drinking water after the third basin.
\end{abstract}

Keywords: Water Desalination, Innovative Techniques for Desalination, Biological Desalination, Desalination by Algae

\section{Introduction}

Several microorganisms are applied to remove salts from water. Some artificial bacteria, which are still under research, were applied for water desalination 3 years ago. Also, some algae spices from 5 years ago started to be applied under research manner to desalinate sea water with successful promising results.

Algae are simple plants without roots, stems, and leaves contain chlorophyll. They are a heterogeneous group of organisms and vary in size from microscopic unicellular forms to sea weeds of many feet in length with many different shapes. Algae kinds grow wherever in water either salinity water in seas or fresh water in rivers and lakes and under different weathers from snow weather to hot climatic, wherever they could synthesize their components and food by photo-synthesis [1].

Scendesmus species growth was successfully obtained in saline water as it absorbs salts and makes use of them in its metabolism, while Chlorella and Scenedesmus are described as the most active Algae in stabilization ponds, because they are extremely, and commonly exhibit extremely wide range of salt tolerance in their habitat. [2]

Micro-algae have a high capacity for inorganic nutrient uptake and can be used in mass culture in outdoor solar bioreactors. Unicellular green algae such as Chlorella and Scendesmus have been widely used in wastewater treatment because the often colonize the ponds naturally, and they have fast growth rates and high nutrient uptake capabilities. However, one of the major drawbacks of using micro-algae in wastewater treatment is the harvesting of biomass. [3]

Green algae was used for treatment of industrial wastewater from natural gas production fields of $1500 \mathrm{~m}^{3}$ daily flow, which contains salinity up to $25000 \mathrm{ppm}$ and oil content up to $100 \mathrm{ppm}$. The effluent could be re-used in irrigation of crops with a flow enough for about 60 fed./day. While the produced algae 1.5 ton/day that could be used in medical industry, pigments for industry, functional food, biofertilizers, and animal or fish fodders [4].

Another algae application in stabilization ponds for industrial wastewater treatment of high salinity and oil content was made through a pilot plant which was built in the site of N/D field in Abu-Mady north of Egypt. Several runs 
were made to ensure the results. The influent loads were varied between $35000 \& 10900$ ppm for TDS, $250 \& 65$ ppm for Oil, $212 \& 59 \mathrm{ppm}$ for BOD \& $344 \&$ 88ppm for COD. The effluent concentrations after 7 days retention time in the pond were ranged between $2750 \& 2120$ ppm for TDS, $2 \&$ $0.5 \mathrm{ppm}$ for Oil, 7,4 ppm for BOD \& $16 \& 12 \mathrm{ppm}$ for COD. These removal efficiencies proved the suitability of algae application for saline industrial wastewater treatment [5].

Desalination based on the use of algae in the removal of salts from saline water, and water production for use in different purposes is a new concept and it has been used and tested in previous researches in industrial waste water treatment, where using the algae reduced the cost to the minimum while maintained the efficiency with no reduction. The achieved results were promising and good in the desalination of sea water and is successful, continuing to reach the removal efficiency up to $95 \%$ till the rates are relatively affordable for possible use in different purposes, opening the door to a new direction may succeed in solving the problem of water desalination with cost reduction to the minimum possible [6].

A study was made to assess the removal efficiencies of different nutrients in saline water by the means of the green algae Scendesmus species. Total dissolved solids, Sodium, Chloride, and Phosphate removal efficiencies measured in the output of the reactor after 14 days reached around $97 \%$. While the removal efficiencies of both Nitrate and Sulfate reached around 93\% and all the parameters in the effluent were inside the permissible limits for potable water except the presence of some enzymes due to algae decay. This shows the success of this system to produce suitable potable water from sea water. [7]

In March 2011, another study was made. The objective of this study was to assess the removal efficiencies of different nutrients in saline water by the means of the green algae Scendesmus species through a continuous flow treatment system. The saline water from Red Sea, Ismailia Governorate (about $40000 \mathrm{ppm}$ ) was used. Algae were added to two consecutive reactors in which a 7 days retention time was applied in each to prevent the enzymes formations in the basins. The experiment in the continuous flow was repeated for 4 runs and the average values were taken into consideration Analysis of growth media was daily determined. Total dissolved solids, Sodium, Chloride, and Phosphate removal efficiencies measured in the output of the second reactor reached around $97 \%$. While the removal efficiencies of both Nitrate and Sulfate reached around 93\% $[8,9]$.

El Hosseiny, O.M., et al,[10] in their study proved the suitability of applying algae for biological desalination under nature Egyptian conditions with high removal ratios for TDS depending on the inlet water salinity and both of the sunlight period and the temperature.

\section{Materials \& Methods}

A new system for water desalination was applied by using Algae for a natural, environment friendly and economic desalination. The Scendesmus algae species was the choice for operation process, thanks to its natural feature of growing very well in almost any mineral medium. The application was successfully worked under suitable conditions inside the lab as illustrated by El Nadi [5][6][9], El Sergany [5][6], Saad [7] \& Badawy [8]. In this study the system is built outside the lab to meet the normal nature conditions.

The pilot plant located on the roof of the Material Lab of the Ain Shams university engineering faculty specified for open air pilots. The pilot plant consists of three storage tanks, three basins each divided to three equal paths and equipped with manual algae separators units. Figure (1) illustrates the pilot photo

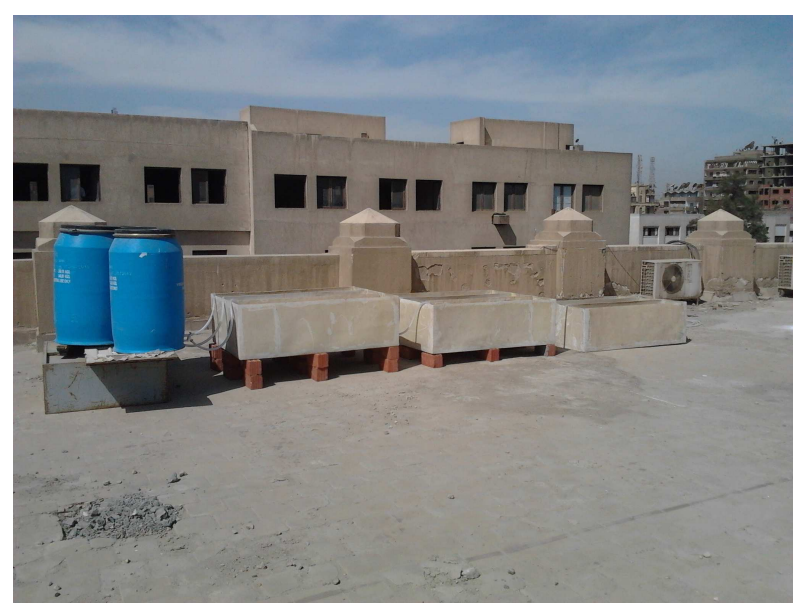

Fig (1). Photo of the applied Pilot for algae Ponds

The pilot plant was operated from February 2013 till June 2013 to obtain the system suitability. It consisted of three runs, each with three different TDS concentrations for the three parts of each basin. Several concentrations of saline water 2000, 4000, 10000, 15000, 20000, 25000, 30000, $35000 \& 40000 \mathrm{ppm}$ were applied three in each run. The feeding media for algae BG-11 solution was added to give algae enough nutrition with rate $0.1 \mathrm{lit} / \mathrm{path} / \mathrm{run}$. Scendesmus algae were added by rate $0.4 \mathrm{lit} / \mathrm{path} / \mathrm{run}$ to treat the saline water for a retention time of 7 days in first basin. Water after separating algae in the first basin was then transferred to the second basin. Scendesmus algae in second basin did the second stage of treatment for another 7 days. Then the work repeated in the third basin. Desalinated water was collected in the effluent after the third basin. Table (1) shows the chemical composition of BG-11 nutrient solutions.

Table (1). Chemical composition of BG-11 nutrient solutions [6]

\begin{tabular}{ll}
\hline Chemical & BG-11(g/l) \\
\hline $\mathrm{NaNO}_{3}$ & 1.5 \\
$\mathrm{~K}_{2} \mathrm{HPO}_{4} 3 \mathrm{H}_{2} \mathrm{O}$ & 0.04 \\
$\mathrm{Na}_{2} \mathrm{CO}_{3}$ & 0.02 \\
$\mathrm{MgSO}_{4} \cdot 7 \mathrm{H}_{2} \mathrm{O}$ & 0.075 \\
$\mathrm{CaCl}_{2} \cdot 2 \mathrm{H}_{2} \mathrm{O}$ & 0.036 \\
$\mathrm{EDTA}-\mathrm{Na}_{2}$ & 0.001 \\
$\mathrm{Fe}\left(\mathrm{NH}_{3}\right)_{2}$ Citrate & 0.006 \\
Citric acid & 0.006 \\
\hline
\end{tabular}


Samples were taken each day from each part of each basin, as well as the effluent tank. The sample volume was $50 \mathrm{ml}$. Water samples were routinely collected at 9:00 am each morning and analyzed to investigate water quality during the examination period. The measured parameters were as Total dissolved solids (TDS), Air Temperature, Humidity, Sunlight period \& Algae growth rate.

\section{Results \& Discussions}

The first run started with small salts concentrations. The feeding tanks had concentrations of 2000, 4000 and 10000 $\mathrm{mg} / \mathrm{l}$. The run was applied for 21 days through the three basins for the three parallel lines.

The study measured the TDS concentrations at each basin effluent in addition to the climatic conditions during the run operation days. The results of the measured data during First, second \& third runs are shown in tables (2), (3) \& (4)

The pilot was found successful in removing TDS concentrations from the medium using Algae with BG11 media and under Natural variable conditions. However, the Removal efficiencies average differed according to inlet TDS concentration. Table (5) and figure (2) illustrated the variations in removal ratios due to the inlet TDS concentration.

Table (2). Measured Parameters during First Run

\begin{tabular}{|c|c|c|c|c|c|c|c|c|}
\hline \multirow{3}{*}{ Basin } & \multirow{3}{*}{ Date } & \multicolumn{4}{|c|}{ Air Climatic Conditions } & \multicolumn{3}{|c|}{ TDS mg/l } \\
\hline & & \multicolumn{2}{|c|}{ Temperature ${ }^{\circ} \mathrm{C}$} & \multirow{2}{*}{ Humidity \% } & \multirow{2}{*}{ Sun Light Period (hr) } & \multirow{2}{*}{ Left Basin } & \multirow{2}{*}{ Middle Basin } & \multirow{2}{*}{ Right Basin } \\
\hline & & Day & Night & & & & & \\
\hline \multirow{6}{*}{ Basin 1} & $1 / 3 / 13$ & 21 & 11 & 54 & 12.00 & 2000 & 4000 & 10000 \\
\hline & $2 / 3 / 13$ & 28 & 12 & 42 & 12.02 & 1020 & 3200 & 7920 \\
\hline & $3 / 3 / 13$ & 29 & 17 & 22 & 12.05 & 920 & 2920 & 6130 \\
\hline & $4 / 3 / 13$ & 21 & 15 & 57 & 12.07 & 890 & 2610 & 5080 \\
\hline & $5 / 3 / 13$ & 19 & 12 & 60 & 12.10 & 860 & 2370 & 4000 \\
\hline & $7 / 3 / 13$ & 23 & 9 & 44 & 12.15 & 780 & 1730 & 2990 \\
\hline \multirow{6}{*}{ Basin 2} & $8 / 3 / 13$ & 27 & 12 & 34 & 12.18 & 780 & 1730 & 2990 \\
\hline & $9 / 3 / 13$ & 23 & 14 & 63 & 12.20 & 730 & 1460 & 2420 \\
\hline & $10 / 3 / 13$ & 27 & 13 & 46 & 12.22 & 690 & 1190 & 2000 \\
\hline & $11 / 3 / 13$ & 30 & 17 & 30 & 12.25 & 650 & 980 & 1709 \\
\hline & $12 / 3 / 13$ & 34 & 22 & 18 & 12.28 & 620 & 910 & 1410 \\
\hline & $13 / 3 / 13$ & 28 & 17 & 51 & 12.30 & 600 & 840 & 1209 \\
\hline \multirow{7}{*}{ Basin 3} & $15 / 3 / 13$ & 22 & 17 & 27 & 12.35 & 580 & 790 & 1170 \\
\hline & $16 / 3 / 13$ & 20 & 15 & 53 & 12.37 & 510 & 750 & 950 \\
\hline & $17 / 3 / 13$ & 14 & 14 & 48 & 12.40 & 450 & 710 & 850 \\
\hline & $18 / 3 / 13$ & 22 & 12 & 52 & 12.43 & 400 & 680 & 770 \\
\hline & $19 / 3 / 13$ & 24 & 11 & 57 & 12.46 & 380 & 650 & 730 \\
\hline & $20 / 3 / 13$ & 31 & 12 & 57 & 12.50 & 360 & 630 & 700 \\
\hline & $21 / 3 / 13$ & 25 & 12 & 47 & 12.54 & 340 & 610 & 680 \\
\hline
\end{tabular}

Table (3). Measured Parameters during Second Run

\begin{tabular}{|c|c|c|c|c|c|c|c|c|}
\hline \multirow{3}{*}{ Basin } & \multirow{3}{*}{ Date } & \multicolumn{4}{|c|}{ Air Climatic Conditions } & \multicolumn{3}{|c|}{ TDS mg/l } \\
\hline & & \multicolumn{2}{|c|}{ Temperature ${ }^{\circ} \mathrm{C}$} & \multirow{2}{*}{ Humidity \% } & \multirow{2}{*}{ Sun Light Period (hr) } & \multirow{2}{*}{ Left Basin } & \multirow{2}{*}{ Middle Basin } & \multirow{2}{*}{ Right Basin } \\
\hline & & Day & Night & & & & & \\
\hline \multirow{7}{*}{ Basin 1} & $1 / 4 / 13$ & 28 & 21 & 29 & 12.57 & 20000 & 30000 & 40000 \\
\hline & $2 / 4 / 13$ & 28 & 16 & 34 & 13.00 & 13840 & 27030 & 34060 \\
\hline & $3 / 4 / 13$ & 32 & 19 & 28 & 13.04 & 9260 & 20200 & 29050 \\
\hline & $4 / 4 / 13$ & 23 & 16 & 53 & 13.07 & 7370 & 13270 & 22980 \\
\hline & $5 / 4 / 13$ & 24 & 15 & 52 & 13.10 & 6130 & 8960 & 14460 \\
\hline & $6 / 4 / 13$ & 29 & 13 & 40 & 13.14 & 5280 & 7340 & 9320 \\
\hline & $7 / 4 / 13$ & 35 & 19 & 22 & 13.17 & 4050 & 6220 & 7830 \\
\hline \multirow{7}{*}{ Basin 2} & $8 / 4 / 13$ & 26 & 18 & 2 & 13.20 & 4050 & 6220 & 7830 \\
\hline & $9 / 4 / 13$ & 24 & 16 & 8 & 13.23 & 3240 & 5130 & 6120 \\
\hline & $10 / 4 / 13$ & 23 & 14 & 10 & 13.27 & 2890 & 4240 & 4980 \\
\hline & $11 / 4 / 13$ & 23 & 14 & 8 & 13.30 & 1940 & 3480 & 4020 \\
\hline & $12 / 4 / 13$ & 24 & 13 & 9 & 13.33 & 1330 & 3170 & 3250 \\
\hline & $13 / 4 / 13$ & 24 & 13 & 10 & 13.36 & 950 & 2760 & 3080 \\
\hline & $14 / 4 / 13$ & 28 & 14 & 11 & 13.39 & 890 & 2590 & 2840 \\
\hline \multirow{7}{*}{ Basin 3} & $15 / 4 / 13$ & 29 & 14 & 48 & 13.42 & 890 & 2590 & 2840 \\
\hline & $16 / 4 / 13$ & 23 & 15 & 54 & 13.45 & 850 & 2260 & 2320 \\
\hline & $17 / 4 / 13$ & 22 & 15 & 53 & 13.47 & 810 & 1920 & 1980 \\
\hline & $18 / 4 / 13$ & 23 & 14 & 52 & 13.49 & 770 & 1580 & 1609 \\
\hline & $19 / 4 / 13$ & 23 & 14 & 49 & 13.51 & 730 & 1290 & 1330 \\
\hline & $20 / 4 / 13$ & 22 & 14 & 44 & 13.53 & 690 & 1090 & 1150 \\
\hline & $21 / 4 / 13$ & 21 & 14 & 51 & 13.55 & 640 & 900 & 920 \\
\hline
\end{tabular}


Table (4). Measured Parameters during Third Run

\begin{tabular}{|c|c|c|c|c|c|c|c|c|}
\hline \multirow{3}{*}{ Basin } & \multirow{3}{*}{ Date } & \multicolumn{4}{|c|}{ Air Climatic Conditions } & \multicolumn{3}{|c|}{ TDS mg/l } \\
\hline & & \multicolumn{2}{|c|}{ Temperature ${ }^{\circ} \mathrm{C}$} & \multirow{2}{*}{ Humidity \% } & \multirow{2}{*}{ Sun Light Period (hr) } & \multirow{2}{*}{ Left Basin } & \multirow{2}{*}{ Middle Basin } & \multirow{2}{*}{ Right Basin } \\
\hline & & Day & Night & & & & & \\
\hline \multirow{7}{*}{ Basin 1} & $1 / 5 / 13$ & 35 & 18 & 35 & 14.10 & 25000 & 35000 & 40000 \\
\hline & $2 / 5 / 13$ & 32 & 19 & 43 & 14.12 & 15160 & 30090 & 33480 \\
\hline & $3 / 5 / 13$ & 32 & 19 & 51 & 14.14 & 10470 & 24540 & 28270 \\
\hline & $4 / 5 / 13$ & 36 & 19 & 46 & 14.16 & 7920 & 15480 & 22120 \\
\hline & $5 / 5 / 13$ & 34 & 19 & 39 & 14.18 & 6300 & 10760 & 13540 \\
\hline & $6 / 5 / 13$ & 33 & 19 & 42 & 14.20 & 4880 & 8130 & 8720 \\
\hline & $7 / 5 / 13$ & 33 & 20 & 51 & 14.22 & 3940 & 7250 & 7630 \\
\hline \multirow{7}{*}{ Basin 2} & $8 / 5 / 13$ & 31 & 20 & 56 & 14.24 & 3940 & 7250 & 7630 \\
\hline & $9 / 5 / 13$ & 31 & 20 & 52 & 14.26 & 3330 & 5820 & 6010 \\
\hline & $10 / 5 / 13$ & 33 & 21 & 48 & 14.28 & 2690 & 4210 & 4580 \\
\hline & $11 / 5 / 13$ & 30 & 20 & 41 & 14.3 & 2480 & 3370 & 3730 \\
\hline & $12 / 5 / 13$ & 27 & 19 & 53 & 14.32 & 2130 & 2740 & 3070 \\
\hline & $13 / 5 / 13$ & 34 & 21 & 34 & 14.34 & 1840 & 2560 & 2750 \\
\hline & $14 / 5 / 13$ & 27 & 18 & 42 & 14.36 & 1620 & 2280 & 2520 \\
\hline \multirow{7}{*}{ Basin 3} & $15 / 5 / 13$ & 27 & 19 & 42 & 14.38 & 1620 & 2280 & 2520 \\
\hline & $16 / 5 / 13$ & 28 & 18 & 52 & 14.4 & 1370 & 1950 & 2240 \\
\hline & $17 / 5 / 13$ & 32 & 20 & 55 & 14.42 & 1010 & 1670 & 1960 \\
\hline & $18 / 5 / 13$ & 34 & 20 & 41 & 14.43 & 860 & 1410 & 1600 \\
\hline & $19 / 5 / 13$ & 38 & 22 & 36 & 14.45 & 810 & 1130 & 1310 \\
\hline & $20 / 5 / 13$ & 33 & 21 & 28 & 14.46 & 750 & 860 & 1170 \\
\hline & $21 / 5 / 13$ & 33 & 21 & 50 & 14.48 & 690 & 830 & 880 \\
\hline
\end{tabular}

Table (5). TDS Removal Ratio

\begin{tabular}{cccc}
\hline \multirow{2}{*}{ Time (days) } & \multicolumn{3}{c}{ Average Removal Efficiency \% } \\
\cline { 2 - 4 } & Inlet TDS Above 20000 ppm & Inlet TDS Between 20000 and 1000 ppm & Inlet TDS Below 1000 ppm \\
\hline 1 & 0.0 & 0.0 & 0.0 \\
2 & 20.9 & 17.6 & 7.0 \\
3 & 38.5 & 31.9 & 13.3 \\
4 & 55.0 & 43.4 & 18.8 \\
5 & 68.9 & 52.1 & 22.7 \\
6 & 76.9 & 58.1 & 25.9 \\
7 & 80.6 & 62.3 & 29.5 \\
\hline
\end{tabular}

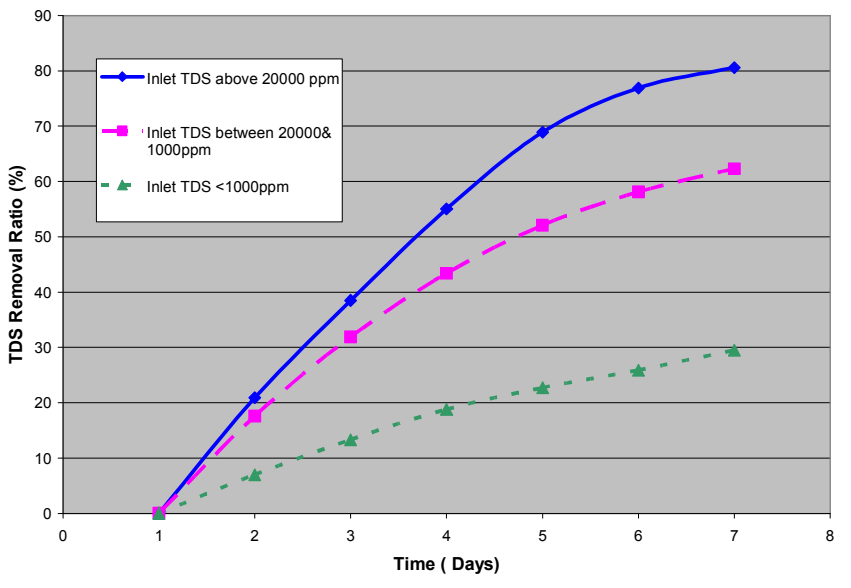

Figure (2). TDS Removal Ratio with time for different inlet TDS concentrations

From previous Table \& figure, it is obvious that the removal efficiency increases with the increase of TDS. In other words, the removal efficiency average is directly proportional to the starting TDS concentration.

The results are showing the same trend from previous work made inside lab [6, 7, 8 \& 9]. There is some deviation though which is occurring because of the effect of the nature condition of the day and night periods which was not applied in laboratory work.

In El Nadi et al [9] work, TDS average removal efficiency by $81.3 \%$ was achieved in 7 days in laboratory condition for any inlet TDS concentration. But in this study, three categories had been seen due to the inlet TDS concentration, the first for TDS more than 20000 ppm that achieved maximum removal ratio $77 \%$ in 7 days. The second for inlet TDS between 20000 and 1000 ppm and obtained maximum removal ratio of $64.7 \%$ and the third for inlet TDS less than $1000 \mathrm{ppm}$ that reached maximum removal efficiency $28.1 \%$.

These variations could be explained for the effect of Temperature variations and the effect of sun light period differences in the nature circumstances.

This was also noticed on the continuous flow ponds system that the removal efficiency was very high in the first 
basin then decreased in the second one and be very slow changed in the third basin as shown in figure (3).

In figure (3), the shown TDS values resemble the average TDS values present in the three basins in series when starting with TDS of $40000 \mathrm{ppm}$. The behavior of Algae appears to be very effective in the first basin, and it decreases after in the second before turning to nearly constant in the third basin.

For the continuous flow pond system it was noticed that with inlet TDS $40000 \mathrm{ppm}$, the overall efficiency of the 3 basins reached $97.7 \%$, while the efficiency of the first two basins alone reached $93 \%$ while first basin alone achieved $80.6 \%$.

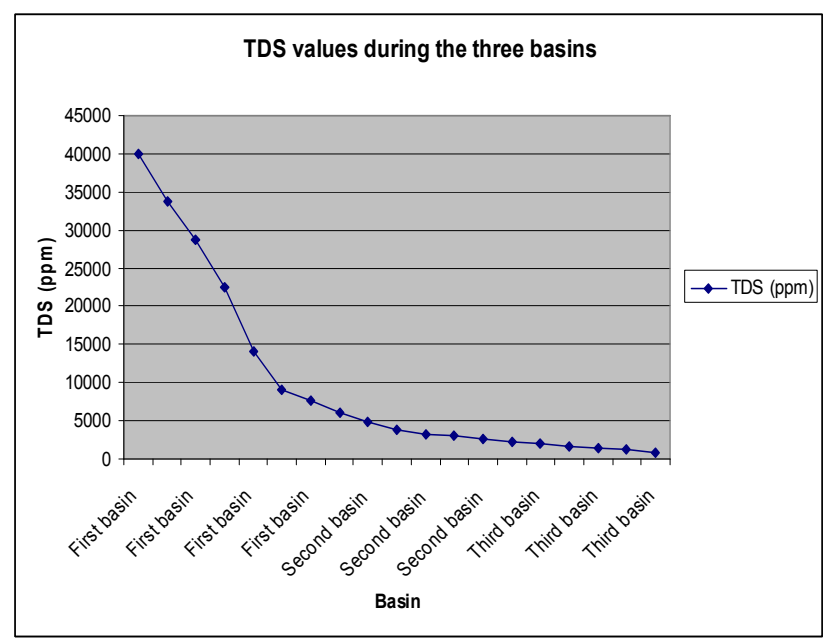

Figure (3). TDS values all through the three basins

\section{Conclusions}

Generally, results encourage the use of green algae for desalination and put an easy equation for the system design. The study had shown the following specific conclusions:-

1 The continuous flow algae ponds in the field under nature variable conditions achieved high removal for TDS from sea water.

2 Scendesmus species growth was successfully obtained in saline water as it uptakes salts and make use of them in its metabolism.

3 The effectiveness of the system increase as the starting total dissolved solids content increases. It was with high removal efficiency when TDS was above $20000 \mathrm{ppm}$. It was with moderate removal efficiency when TDS was between 20000 and 1000 ppm. And it was with low removal efficiency when TDS was below 1000 ppm.

4 The system efficiency affected mainly with the inlet TDS concentration.

5 For more removal for salinity second or third reactor could be applied with successful results.

6 The effect of the nature conditions of temperature, sunlight period was noticeable by about $5-15 \%$ lower in removal efficiency compared with the previous work made inside the laboratory

7 The advantages of the proposed continuous flow system are low cost, easy construction with low operation \& maintenance cost, and low energy requirements.

8 The system gives low pollution to surrounding environment, with maximum benefit of by-products, besides it solves the problem of getting rid of the waste products.

\section{References}

[1] Pelczar, M.J. and Reid , R.D., "The Algae",: Mc-graw - Hill Book Company, N.Y., USA 1965.

[2] Gimmler. "The Metabolic Response of the Halotolerant Green Alga Dunalella parva to Hypertonic Shocks". Gottingen : Ber. Deutsch.Bot. Ges. Bd., Vol. 94, 1981.

[3] G, Laliberte, et al., "Effect of Phosphorus Addition on Nutrient Removal from Wastewater with the Cyanobacterium Phprmidium bohneri" . s.l. : Bioresource Technol, Vol. 59. 227-233,1997.

[4] Ibrahim, M.S., "Reuse and Recycle of Wastewater in Natural Gas Industry.", PhD Thesis, Inst. Of Environmental Studies \& Researchs, ASU, Cairo, Egypt , 2005.

[5] El Nadi, M. H., El Sergany, F.A. R \& Ibrahim, M.S.M., "Use of Algae for Wastewater Treatment In Natural Gas Industry.", ASU, Faculty of Engineering Scientific Bulliton, Vol.1.,16871695, Cairo, Egypt, September 2008.

[6] El Nadi, M. H., El Sergany, F.A. GH. R "Water Desalination by Algea", .ASU Journal of Civil Engineering Vol. 2., pp 105-114, September 2010.

[7] El Nadi, M.H. A., Waheb, I.S. A., Saad, S. A.H.A.,"USING CONTINUOUS FLOW ALGAE PONDS FOR WATER DESALINATION ", El Azhar Univ., Faculty of Eng., CERM of civil Eng., vol. 33, No. 4, December, 2011.

[8] Badawy M.A., El Nadi, M.H. \& Nasr, N.A.H.," BIOLOGICAL DESALINATION TECHNIQUE BY ALGAE APPLICATION", Ain Shams Univ., Institute for Environmental Studies and Research, Journal of Environmental Science, vol. 17, No. 4, December, 2011.

[9] El Nadi, M.H., Nasr, N.A.H., El Hosseiny, O.M. \& Badawy M.A., "ALGAE APPLICATION FOR BIOLOGICAL DESALINATION.", $2^{\text {nd }}$ International Conference \& Exhibition, Sustainable water supply \& sanitation, (SWSSC2012), holding company for water and wastewater, Cairo, Egypt, December. 2012.

[10] El Hosseiny, O.M., El Nadi, M.H., Fergala, M.A.A. \& El Khouly, M.S.M., "Water Desalination by Continuous Flow Algae Ponds under nature conditions.", El Azhar Univ., Faculty of Eng., CERM of civil Eng., vol. 35, No. 4, October 2013. 